\title{
INHALTSVERZEICHNIS
}

Text und Übersetzung

Buch VII .............................. 6

Buch VIII .............................. II6

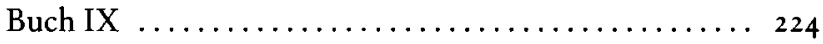

Buch X ............................ 356

Die antiken Inhaltsangaben von Buch VII-X ........ 480

Die antiken Inhaltsangaben und die Fragmente

der Bücher XI-XX ........................ 488

Aus der Chronik Cassiodors ................... 508

Kondordanz zu den Fragmenten der zweiten Dekade .. 509

Zur Textgestaltung $\ldots \ldots \ldots \ldots \ldots \ldots \ldots \ldots \ldots \ldots \ldots \ldots$ sio

Erläuterungen $\ldots \ldots \ldots \ldots \ldots \ldots \ldots \ldots \ldots \ldots \ldots \ldots \ldots \ldots \ldots \ldots \ldots$

Einführung in die Bücher VII-X des Livius .......... 6Is

Zur zweiten Dekade $\ldots \ldots \ldots \ldots \ldots \ldots \ldots \ldots \ldots, 6 \varsigma_{52}$

Literaturhinweise ....................... 662

Inhaltsübersicht und Parallelüberlieferung .......... 667

Zeittafel ................................ 679

Die Konsuln, Diktatoren und Magistri equitum

von 366 bis 293 v. Chr.....................6 68 I

Verzeichnis der Eigennamen .................. 687 


\section{LIBER VII}

Annus hic erit insignis novi hominis consulatu, insignis novis duobus magistratibus, praetura et curuli aedilitate. Hos sibi patricii quaesivere honores pro concesso plebi altero consulatu. Plebes consulatum L. Sextio, cuius lege partus erat, dedit; patres praeturam Sp. Furio Marci filio Camillo, aedilitatem Cn. Quinctio Capitolino et P. Cornelio Scipioni, suarum gentium viris, gratia campestri ceperunt. L. Sextio collega ex patribus datus L. Aemilius Mamercus.

Principio anni et de Gallis, quos primo palatos per Apuliam congregari iam fama erat, et de Hernicorum defectione agitata mentio. Cum de industria omnia, ne quid per plebeium consulem ageretur, proferrentur, silentium omnium rerum ac iustitio simile otium fuit, nisi quod non patientibus tacitum tribunis, quod pro consule uno plebeio tres patricios magistratus curulibus sellis praetextatos tamquam consules sedentes nobilitas sibi sumpsisset, praetorem quidem etiam iura reddentem et collegam consulibus atque iisdem auspiciis creatum, verecundia inde imposita est senatui ex patribus iubendi aediles curules creari. Primo, ut alternis annis ex plebe fierent, convenerat; postea promiscuum fuit.

Inde L. Genucio et $Q$. Servilio consulibus et ab seditione et a bello quietis rebus, ne quando a metu ac periculis vacarent, pestilentia ingens orta. Censorem, aedilem curulem, tres tribunos plebis mortuos ferunt, pro portione et ex multitudine alia multa funera fuisse; maximeque eam pestilentiam insignem mors quam matura, tam acerba $M$. Furi fecit. 